\title{
Longer Patents For Lower Imitation Barriers: The 1984 Drug Act
}

\author{
By Henry Grabowski and John Vernon*
}

On September 24, 1984, President Reagan signed into law the Drug Price Competition and Patent Term Restoration Act of 1984. This law, the first change in United States patent terms since 1861, restores part of the patent life lost during the premarket regulatory process for new pharmaceuticals (and also for medical devices and food additives). A second major provision of the law facilitates the entry of generic competitors after patent expiration.

The adverse impacts on pharmaceutical $R \& D$ of the 1962 Kefauver Amendents to the Food, Drug, and Cosmetic Act have been well documented (for a survey, see our 1983 book). These regulations have been a significant factor underlying increasing $R \& D$ costs, longer gestation periods, and shorter patent terms in pharmaceuticals. At the present time, average effective patent life for new pharmaceuticals is approximately half of the statutory life of 17 years. The 1984 Act would increase patent life up to 5 years using a formula approach analyzed in Section II below.

The adverse impacts of regulatory requirements on the entry of generic products in pharmaceuticals have not been well documented. In particular, generic products frequently could not rely on the safety and efficacy evidence submitted by the pioneer firms for post-1962 drug introductions. These data were accorded trade secret status. Consequently, unless the relevant data were publicly available in the scientific literature, an imitator had to duplicate many of the pioneer's tests to gain market approval. Under the new law, a generic drug company need only submit an "Abbreviated New Drug Application" (ANDA). This requires it only

*Department of Economics, Duke University, Durham, NC 27706. to demonstrate that the drug is bioequivalent to the pioneer's product, a relatively low cost experiment.

The Drug Price Competition and Patent Term Restoration Act of 1984 has been termed the most important legislation for the pharmaceutical industry since the 1962 Kefauver Amendments. Essentially, it eliminates duplicative testing and makes entry easy for generic competitors, while at the same time extending patent protection for future new product introductions. In this paper we analyze its likely impacts on competition in the pharmaceutical industry, the incentives for innovation, and general consumer welfare.

\section{The Impact of ANDAs on Market Entry}

There is evidence to indicate that the requirement that generics duplicate the pioneer's safety and efficacy tests was a significant and growing barrier to entry in recent years. While clinical studies done at medical centers are often published, in-house animal toxicity studies are not. At a minimum, therefore, generic firms had to duplicate these latter studies. It has been estimated in the trade literature that a new drug application for a generic firm potentially involved expenditures of several million dollars and testing periods of 2 years or more.

In order to gain insights into how important this was as an entry barrier, we analyzed 1983 data on the number of drugs among the top 200 pharmaceuticals with expired patents that also had no generic competitors. Antibiotics and pre-1962 introductions were excluded from this analysis because they were governed by separate procedures that did not require duplicate safety and efficacy testing. We found that 34 of the 52 drugs in the sample with expired patents had no generic competition, or 65 percent of 
the total. Among the drugs without generic competition were 2 of the top 20 selling products. These 2 drugs had combined sales in 1983 of over $\$ 200$ million and had patents that expired in 1980 and 1981.

The experience with respect to generic entry for pre-1962 drug introductions and antibiotics was markedly different. We found that over 90 percent of these drugs with expired patents in 1983 had generic competitors. Overall our results indicate that the testing requirement was a significant entry barrier at the time the new legislation was passed.

The Act is particularly timely because there have been a number of complementary developments in recent years operating to encourage increased use of generic drug products. First, all of the state antisubstitution laws prohibiting pharmacists from deviating from physician brand-name prescriptions have now been repealed. Second, third-party payers such as governments, Blue Cross-Blue Shield, and the private health insurers have initiated procedures to limit payment to lower-priced alternatives. Third, the spread of Health Maintenance Organizations has encouraged the use of generic drugs. Finally, consumers have become more conscious of generic drugs as large chain drug stores have aggressively promoted these products (generics generally have higher margins to pharmacists).

The experience of two leading pharmaceuticals, Valium and Inderal, that have experienced generic competition for the first time this year illustrates these trends. These 2 drugs have lost approximately onequarter of their respective market shares on new prescriptions to generic products selling at price discounts of 20 percent or more. This has occurred within the first 3 months of generic availability. Another leading pharmaceutical, Indocin, has lost approximately half its market share in only its second year of generic competition. These rates of sales losses are far in excess of historical patterns in pharmaceuticals, or what was experienced only a few years ago.

If these numbers are at all representative, the Act has removed a significant entry barrier with enormous financial implications for the pharmaceutical industry and consumers of prescription medicines. In this regard, we calculated that pharmaceuticals with sales of over $\$ 2.5$ billion in a total market of approximately $\$ 13$ billion will be subject to market entry via the ANDA procedure during the first year of the new legislation alone. If we take a somewhat longer perspective, 180 of the top 200 pharmaceuticals in 1983 will be subject to generic competition by the end of 1989. This is in very dramatic contrast to the start of the decade when generic competition was largely confined to pre-1962 drug introductions and antibiotics, and "firstmover" advantages were generally strong even for those products experiencing generic competition.

From the perspective of economic welfare, the Act is the source of large potential positive gains along two dimensions. First, it eliminates scientific testing for which there was no valid scientific purpose. Second, it lowers prices significantly to consumers with some elimination of deadweight loss and large transfers from producers to consumers-presumably, a favorable redistribution of income. At the same time, if the Act results in lower market shares and/or lower prices for innovators after patents expire, this could adversely affect the expected returns from $R \& D$ and lead to lower future drug innovations. The patent term restoration aspects of the 1984 Act are designed to ameliorate this potential situation. Whether the added patent term on future introductions is likely to accomplish this objective is an issue to which we now turn.

\section{Patent Extension under the 1984 Act}

The Act provides for an extension in effective patent life equal to the sum of the new drug application review time by the FDA plus one-half the clinical testing time, subject to various constraints. These include a maximum extension of 5 years and no extension beyond 14 years of effective patent life. For drugs already in clinical testing, the maximum extension is 2 years. The law also provides a floor of 5 years protection for all new drugs by not permitting any ANDAs during the first 5 years of market life. 
In order to obtain some insights into how much extra protection the law will provide, we simulated its effect on the patent life of all the new drugs introduced over the period 1976-81. There were 98 new drug introductions over this period. Their average effective patent life was 8.9 years. If these drugs had been eligible for the full benefits of patent term restoration, the mean effective patent life would have been extended by 2.9 years to 11.8 years. There is considerable variation across the sample with 18 drugs receiving zero extension and 35 drugs receiving the maximum 5-year extension (including the ANDA exclusivity protection for drugs whose patents had already expired by the time of introduction). The annual fluctuation in added patent term varies from 2.2 years for 1978 introductions to 4.2 years for 1980 introductions.

\section{The Net Effect on $R \& D$ Incentives}

As discussed above, the Act simultaneously promotes generic competition and restores patent life. In this section we attempt to estimate whether the net effect on incentives to invest in $R \& D$ is positive or negative. Our approach is to take as our baseline case the cash flow for the average new drug discovered and introduced in the United States in the 1970's. We have described elsewhere (1985) the assumptions and data limitations made in developing this baseline case. We wish to compare the Net Present Value (NPV) of the average drug's cash flow for a world without the Act to the $N P V$ with the Act in effect. Of course, two key parameters are the number of years of patent life restored, and the percentage loss of net revenues to generics upon patent expiration.

Figure 1 shows the tradeoffs involved. The baseline case has the net revenues life cycle $a b c d$. The vertical distance $b c$ occurs at time $t^{*}$ when the patent expires. It represents net revenue loss to generics in a world without the Act, that is, in a world where barriers to entry confronting generic firms are significant. The size of this loss for the average drug is the product of two factors: the probability of entry, and the extent of losses

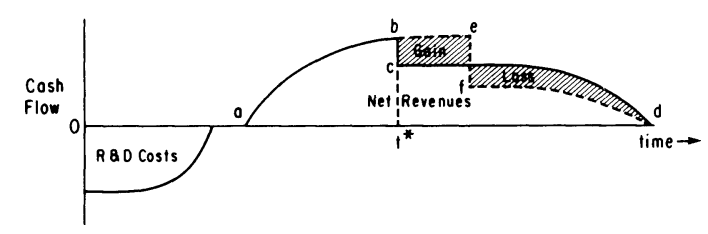

Figure 1. EFFect of 1984 ACt on EXPECTED Net Revenues of Average Drug

given that entry occurs. We assume an upper bound on this loss to be on the order of 20 percent under the prelegislation regime.

In a world with the Act in effect the net revenues life cycle is shown as aefd in Figure 1. Of course, the distance be represents the patent life restored. The vertical distance ef reflects the net revenue loss to generics in a world where generic firms face low entry barriers. Hence, these greater losses to generics as a result of the Act produce the two shaded areas in Figure 1 labled "gain" and "loss." The key issue is then whether the gain or the loss is greater in present value terms.

Given the uncertainty surrounding the two key parameters (the magnitudes of $b e$ and ef ), we provide a sensitivity analysis in Table 1. Using 10 percent as the discount rate, the $N P V$ for the baseline case is computed and set equal to 100 . Three values of patent life restored (1, 3, and 5 years) and three values of net revenue losses to generics $(30,40$, and 50 percent) were selected. For the intermediate case ( 3 years and 40 percent), the $N P V$ is shown in Table 1 as only 93 percent of what the NPV would have been without the Act in effect. In short, for this choice of parameters, the net effect of the Act is estimated to have a moderate negative impact on $R \& D$ investment incentives.

Of course, as Table 1 indicates, the net effect of the Act is positive for three cases. For example, with 3 years of restored patent life and net revenue losses of 30 percent, the Act yields a positive effect with the relative NPV equal to 102. Although our choice of parameter values is necessarily speculative at this time, it does seem fair to say that the tradeoff built into the law is reasonably close - the net effect is not obviously favorable or unfavorable to firms investing in $R \& D$. 
Table 1-Net Present Value For Mean Drug under Alternative AsSumptions about 1984 LAW'S ImPaCT (Net Present Value without Act $=100$ )

\begin{tabular}{lccc}
\hline \hline $\begin{array}{l}\text { Patent } \\
\text { Extension } \\
\text { (years) }\end{array}$ & \multicolumn{3}{c}{ Net Revenue Loss to Generics } \\
\cline { 2 - 4 } & $30 \%$ & $40 \%$ & $50 \%$ \\
\hline 5 & 110 & 104 & 98 \\
3 & 102 & 93 & 84 \\
1 & 91 & 79 & 67 \\
\hline
\end{tabular}

${ }^{\text {a }}$ Shown as distance be in Figure 1.

${ }^{\mathrm{b}}$ Shown as distance ef in Figure 1.

It should be noted that our analysis has dealt with the average drug. Firms that are optimistically seeking "block buster" drugs are unlikely to be deterred by the Act's possibly negative effect on the NPV of the marginal introduction. At the same time, firms that rely heavily on internal funds to fund $R \& D$ are likely to experience significant financial pressures when the patents on major products expire. The Act will also have very different impacts on firms depending on the diversification of existing drug portfolios, dates of patent expiration, new drugs in the pipeline, etc.

\section{Summary and Conclusions}

By eliminating the need for duplicate testing, Drug Price Competition and Patent Term Restoration Act of 1984 should facilitate the rapid entry of generic products. The resulting price reductions to consumers of prescription drugs over the next several years are likely to be substantial. However, the long-run impacts of the Act on innovation are more difficult to assess. Our initial analysis suggests that with an average expected increase in patent life of 3 years, major adverse impacts on the returns to $R \& D$ are unlikely.

\section{REFERENCES}

Grabowski, Henry G. and Vernon, John M., The Regulation of Pharmaceuticals: Balancing the Benefits and Risks, Washington: American Enterprise Institute for Public Policy Research, 1983. and "Pioneers, Imitators, and Generics: A Model of Schumpeterian Competition in the Pharmaceutical Industry," Department of Economics Discussion Paper, Duke University, 1985. 